\section{(6) \\ OPEN ACCESS}

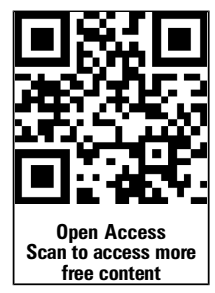

${ }^{1}$ Division of Epigenomics, National Cancer Center Research Institute,

Tokyo, Japan

${ }^{2}$ Endoscopy Division, National

Cancer Center Hospital,

Tokyo, Japan

${ }^{3}$ Epidemiology and Prevention Division, Research Center for

Cancer Prevention and Screening, National Cancer

Center, Tokyo, Japan

${ }^{4}$ Department of Gastroenterology,

University of Tokyo, Tokyo,

Japan

${ }^{5}$ Second Department of

Internal Medicine, Wakayama

Medical University, Wakayama,

Japan

${ }^{6}$ Department of

Gastroenterology and

Hepatology, National Center

for Global Health and

Medicine, Tokyo, Japan

7 Department of

Gastroenterology and

Hepatology, Tokyo Medical

University, Tokyo, Japan

\section{Correspondence to}

Toshikazu Ushiijima,

Division of Epigenomics,

National Cancer Center

Research Institute, 5-1-1

Tsukiji, Chuo-ku, Tokyo

104-0045, Japan;

tushijim@ncc.go.jp

$\mathrm{KA}$ and TN contributed equally.

Received 21 February 2014

Revised 27 April 2014

Accepted 8 May 2014

Published Online First

2 June 2014

To cite: Asada K,

Nakajima T, Shimazu T,

et al. Gut 2015;64:

388-396.

\title{
Demonstration of the usefulness of epigenetic cancer risk prediction by a multicentre prospective cohort study
}

\author{
Kiyoshi Asada, ${ }^{1}$ Takeshi Nakajima, ${ }^{2}$ Taichi Shimazu, ${ }^{3}$ Nobutake Yamamichi, ${ }^{4}$ \\ Takao Maekita, ${ }^{5}$ Chizu Yokoi, ${ }^{2,6}$ Ichiro Oda, ${ }^{2}$ Takayuki Ando, ${ }^{1}$ Takeichi Yoshida, ${ }^{5}$ \\ Sohachi Nanjo, ${ }^{1}$ Mitsuhiro Fujishiro, ${ }^{4}$ Takuji Gotoda, ${ }^{2,7}$ Masao Ichinose, ${ }^{5}$ \\ Toshikazu Ushijima ${ }^{1}$
}

\begin{abstract}
Background Epigenetic alterations accumulate in normal-appearing tissues of patients with cancer, producing an epigenetic field defect. Cross-sectional studies show that the degree of the defect may be associated with risk in some types of cancer, especially cancers associated with chronic inflammation.

Objective To demonstrate, by a multicentre prospective cohort study, that the risk of metachronous gastric cancer after endoscopic resection (ER) can be predicted by assessment of the epigenetic field defect using methylation levels.

Design Patients with early gastric cancer, aged 40-80 years, who planned to have, or had undergone, ER, were enrolled at least 6 months after Helicobacter pylori infection discontinued. Methylation levels of three preselected genes (miR-124a-3, EMX1 and NKX6-1) were measured by quantitative methylation-specific PCR. Patients were followed up annually by endoscopy, and the primary endpoint was defined as detection of a metachronous gastric cancer. Authentic metachronous gastric cancers were defined as cancers excluding those detected within 1 year after the enrolment.
\end{abstract}

Results Among 826 patients enrolled, 782 patients had at least one follow-up, with a median follow-up of 2.97 years. Authentic metachronous gastric cancers developed in 66 patients: 29, 16 and 21 patients at $1-2,2-3$ and $\geq 3$ years after the enrolment, respectively. The highest quartile of the miR-124a-3 methylation level had a significant univariate HR $(95 \% \mathrm{CI})(2.17(1.07$ to 4.41$) ; p=0.032$ ) and a multivariate-adjusted HR ( 2.30 (1.03 to 5.10); $p=0.042$ ) of developing authentic metachronous gastric cancers. Similar trends were seen for EMX1 and NKX6-1.

Conclusions Assessment of the degree of an epigenetic field defect is a promising cancer risk marker that takes account of life history.

\section{INTRODUCTION}

Epigenetic alterations, represented by aberrant DNA methylation, are deeply involved in carcinogenesis. $^{12}$ Aberrant methylation accumulates in cancers and also in normal-appearing tissues, especially those of chronic inflammation-associated cancers, such as gastric cancers, ${ }^{3} 4$ hepatocellular carcinoma, ${ }^{5}{ }^{6}$ oesophageal adenocarcinoma, ${ }^{7} 8$ colon cancers, ${ }^{9}$ colitic cancers ${ }^{10-12}$ and breast cancers. ${ }^{13}$

\section{Significance of this study}

What is already known about this subject?

- Epigenetic alterations, represented by aberrant DNA methylation, accumulate in cancers and also in normal-appearing tissues surrounding cancers.

- Cross-sectional studies show that aberrant methylation levels in normal tissues may be associated with a risk of cancer in some types of cancer, especially chronic inflammation-associated cancers.

- An epigenetic cancer risk marker is considered to reflect past exposure to environmental factors and to differ from single nucleotide polymorphism cancer risk markers that do not reflect life history.

\section{What are the new findings?}

- By a multicentre prospective cohort study with 826 patients, the methylation level in non-cancerous gastric mucosae of patients with gastric cancer was shown to be significantly $(p=0.042)$ associated with an increased risk of developing metachronous gastric cancers.

- miR-124a-3 is an informative marker gene for predicting the risk of developing a metachronous gastric cancer.

How might it impact on clinical practice in the foreseeable future?

- This is the first time that the usefulness of an epigenetic cancer risk marker has been demonstrated in any type of cancer by a multicentre prospective cohort study. This new class of cancer risk marker has the potential to be expanded to cancers of other tissues.

- The intensity of surveillance for metachronous gastric cancer can be adjusted depending upon the risk predicted by the miR-124a-3 methylation level.

In such normal-appearing tissues, both tumoursuppressor genes (driver genes), such as CDKN2A and MLH1 and many other genes that have little 
expression in normal tissues (passenger genes), such as HAND1, are methylated. Driver genes are methylated only at low levelsthat is, in a minor fraction of cells, in normal-appearing tissues. Passenger genes, however, are methylated at high levels-that is, in a large fraction of cells, reflecting the degree of past exposure to inducers of aberrant methylation. ${ }^{3} 14$

The accumulation of such methylation was shown to be associated with a risk of cancer development by cross-sectional studies in the stomach, ${ }^{14}$ the liver, ${ }^{5}{ }^{6}$ the urothelium, ${ }^{15}$ the oesophagus ${ }^{8} 16$ and the colon. ${ }^{17}$ In the stomach, a quantitative methylation analysis of both driver and passenger genes showed that patients with gastric cancer had higher methylation levels in normal-appearing tissues than those in healthy individuals. ${ }^{14} 18$ Furthermore, patients with multiple gastric cancers had significantly higher methylation levels than those with a single gastric cancer, whose methylation levels were higher than those in healthy individuals. ${ }^{19}$ This correlation in the three groups, together with the associations in various types of cancers, strongly supports the suggestion that the accumulation of aberrant methylation in non-cancerous tissues produces an epigenetic field for cancerisation (field defect) and that the presence of such a field is associated with cancer development. ${ }^{3}$

As an inducer of an epigenetic field defect in the stomach, Helicobacter pylori (H. pylori) infection was associated with high methylation levels in gastric mucosae. ${ }^{14}$ Chronic inflammation triggered by the infection was shown to be causally involved in methylation induction in Mongolian gerbils. ${ }^{20}$ It is hypothesised that aberrant DNA methylation is induced in stem, progenitor and differentiated cells when active $H$. pylori infection is present ${ }^{3}$ because eradication of $H$. pylori leads to a decrease of methylation. ${ }^{21-23}$ Importantly, the methylation levels in gastric mucosae without active $H$. pylori infection, but not those in mucosae with active infection, were correlated with gastric cancer risk. ${ }^{14} 1924$ Therefore, measurement of methylation levels in individuals without active $H$. pylori infection is expected to enable us to predict the cancer risk of an individual by analysing the degree of epigenetic field defect.

For incorporation of such a new type of cancer risk marker into practice, demonstration of its usefulness by a multicentre prospective cohort study is requisite. In gastric cancer, a prospective cohort study can be conducted for risk prediction of primary gastric cancer among healthy individuals and for prediction of a metachronous gastric cancer after endoscopic resection (ER). The need for the latter is becoming greater because an increasing number of patients with gastric cancer are now treated by ER and the incidence of metachronous gastric cancer has reached as high as $2.5 \%$ a year, ${ }^{25}$ although eradication of $H$. pylori decreases or delays its occurrence. ${ }^{26}$ Nevertheless, almost all patients treated by ER have similar risk factors and their stratification for future cancer risk has so far been impossible. In addition, this high incidence allows a prospective cohort study with a relatively small number of patients.

Here, we aimed to demonstrate, by a multicentre prospective cohort study, that the risk of metachronous gastric cancer can be predicted by assessment of an epigenetic field defect. This will provide a proof-of-concept that cancer risk prediction can be achieved using the epigenetic field defect.

\section{PATIENTS AND METHODS} Patients

Eligibility was assessed for 964 patients with early gastric cancer aged 40-80 years and who planned to have, or had undergone, endoscopic submucosal dissection, one of the procedures of ER, in one of three hospitals (National Cancer Center Hospital (NCC), Tokyo University Hospital (TYU) and Wakayama Medical University Hospital (WMU)) between 2008 and 2010. Patients were excluded if they had received additional gastrectomy, had cancer in other tissues, died of other diseases before a test for $H$. pylori infection or were receiving anticoagulant therapy and unable to suspend it, refused or had other complications. The remaining 850 patients were tested for $H$. pylori infection. When $H$. pylori infection was absent, they were enrolled at the assessment $(\mathrm{n}=388)$. When $H$. pylori infection was present $(n=462)$, patients received eradication therapy and were enrolled at least 6 months after establishment of successful H. pylori eradication $(n=438)$ (figure 1$)$. A total of 826 patients were enrolled and at the time of enrolment, biopsy samples were taken from a fixed point in the antrum (the lesser curvature at $2 \mathrm{~cm}$ from the pyloric ring) for DNA methylation analysis. Written informed consent was obtained from all the patients and the study was approved by the institutional review boards at each hospital.

\section{Detection of $\boldsymbol{H}$. pylori infection, its eradication and the pepsinogen test}

The presence of $H$. pylori infection was examined with the urea breath test (Otsuka, Tokushima, Japan), serum anti-H. pylori antibody (Eiken, Tokyo, Japan) and either the culture method or rapid urease test (Otsuka, Tokushima, Japan). To eradicate H. pylori, patients were treated with lansoprazole $(30 \mathrm{mg})$, amoxicillin $(750 \mathrm{mg})$ and clarithromycin $(200 \mathrm{mg})$, each taken twice daily for 1 week. Successful eradication was established by negative results of the urea breath test 2 months or more after the eradication. When the eradication was unsuccessful, the patients received second-line eradication therapy. Implementation of third-line and further eradication therapy was left to the doctors in charge. Fasting blood samples were collected on the day of endoscopy at the enrolment and serum levels of pepsinogen I and II were measured by the LZ test (Eiken, Tokyo, Japan).

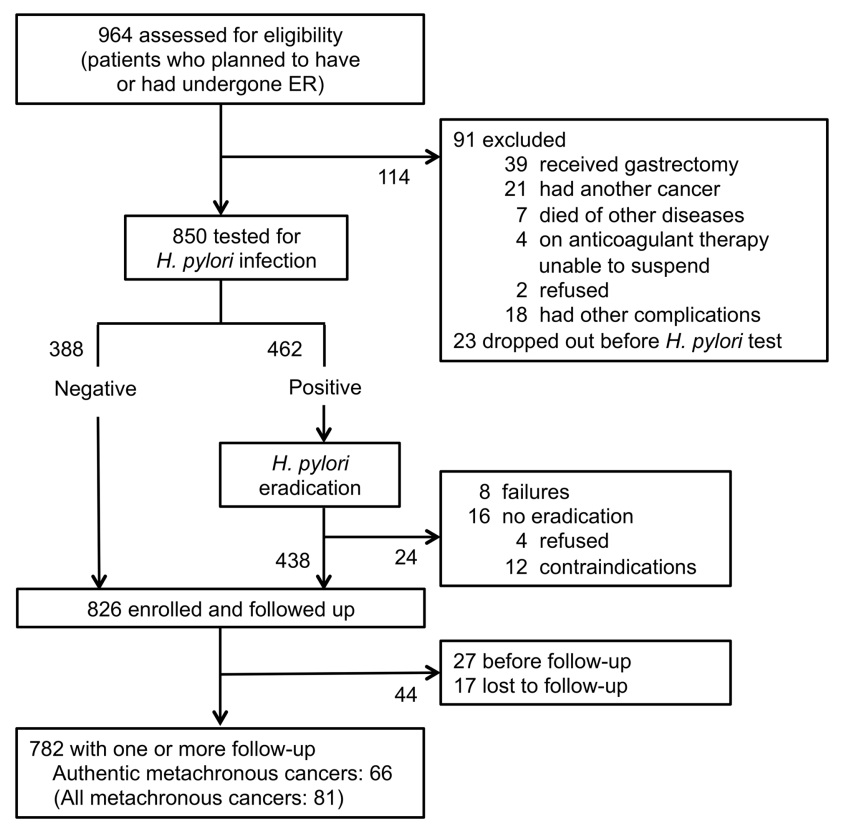

Figure 1 Study profile. ER, endoscopic resection. 
Table 1 Baseline characteristics of patients according to the quartiles of DNA methylation levels of the three genes

\begin{tabular}{|c|c|c|c|c|c|c|c|c|c|}
\hline \multirow[b]{3}{*}{ Characteristic } & \multicolumn{9}{|c|}{ DNA methylation level } \\
\hline & \multicolumn{3}{|l|}{ miR-124a-3 } & \multicolumn{3}{|l|}{$E M X 1$} & \multicolumn{3}{|l|}{ NKX6-1 } \\
\hline & Q1 (lowest) & Q4 (highest) & $\mathrm{p}$ Value & Q1 (lowest) & Q4 (highest) & $\mathrm{p}$ Value & Q1 (lowest) & Q4 (highest) & p Value \\
\hline DNA methylation level, median (IQR) & $14.4(8.3-23.0)$ & $89.8(88.1-91.9)$ & & $11.0(6.3-16.5)$ & $89.7(87.4-91.9)$ & & $37.5(24.9-46.3)$ & $87.3(84.5-90.4)$ & \\
\hline Mean age, years (SD) & $65.8(8.5)$ & $68.6(6.1)$ & 0.0007 & $65.4(8.4)$ & $68.7(6.1)$ & 0.0001 & $66.0(8.2)$ & $68.2(6.7)$ & 0.0247 \\
\hline Male $(\%)$ & 77.4 & 84.1 & 0.3667 & 79.0 & 84.1 & 0.3552 & 80.0 & 82.1 & 0.9434 \\
\hline H. pylori infection before enrolment (\%) & 40.5 & 62.1 & 0.0004 & 39.5 & 54.4 & 0.0041 & 39.5 & 59.0 & 0.0008 \\
\hline \multicolumn{10}{|l|}{ Serum pepsinogen index (\%) } \\
\hline$(+)$ & 5.1 & 8.7 & 0.0010 & 6.2 & 7.2 & 0.0556 & 4.6 & 8.7 & 0.0072 \\
\hline$(2+)$ & 13.9 & 20.0 & & 14.4 & 21.5 & & 19.0 & 18.5 & \\
\hline$(3+)$ & 24.1 & 33.3 & & 21.0 & 27.7 & & 18.5 & 30.3 & \\
\hline \multicolumn{10}{|l|}{ Past history of ER (\%) } \\
\hline Twice & 8.2 & 7.7 & 0.6443 & 9.2 & 10.3 & 0.5077 & 9.2 & 8.7 & 0.9836 \\
\hline Three times & 1.0 & 2.1 & & 1.5 & 2.6 & & 2.1 & 1.5 & \\
\hline \multicolumn{10}{|l|}{ Pack-years of smoking (\%) } \\
\hline $1-39$ & 40.3 & 40.7 & 0.0175 & 39.7 & 41.5 & 0.0050 & 39.1 & 38.7 & 0.6757 \\
\hline$\geq 40$ & 20.4 & 33.9 & & 21.2 & 35.8 & & 26.3 & & \\
\hline \multicolumn{10}{|l|}{ Green vegetable intake (\%) } \\
\hline Almost daily & 28.3 & 36.7 & 0.0070 & 28.7 & 33.5 & 0.0426 & 33.7 & 35.5 & 0.9862 \\
\hline
\end{tabular}

$p$ values $<0.05$ are shown in bold type.

*Based on the $\chi^{2}$ test or the Fisher's exact test for percentage difference and the analysis of variance test for mean age difference.

$E R$, endoscopic resection. 
Follow-up by endoscopy and definition of metachronous cancers

Patients were followed up endoscopically once a year after the enrolment and the primary endpoint was defined as detection of a metachronous gastric cancer. If a patient was lost to follow-up, the follow-up was censored at the time of their last endoscopic examination. Metachronous cancers were defined according to the criteria of Moertel et $a l^{27}$ —namely, (i) each lesion is histopathologically malignant, (ii) each lesion is separated from another and (iii) each lesion is not the result of a local extension or metastasis of other lesions. In particular, 'authentic' metachronous gastric cancers were defined as those found after exclusion of cancers that developed within the first 1 year after the enrolment. This was because there is concern that a gastric cancer developing within the first 1 year after enrolment might have been a cancer undetected at the time of the emrolment ${ }^{28-30}$ and might be influenced by the promoting effect of $H$. pylori infection. ${ }^{26}$

\section{Marker genes and quantitative methylation analysis}

Three marker genes (miR-124a-3, EMX1 and NKX6-1) were preselected in our previous cross-sectional studies, ${ }^{31} 32$ and no other marker genes were analysed to avoid multiple testing. $m i R-124 a-3$ was previously identified as a gene whose methylation levels remain high, even in individuals with past $H$. pylori infection. ${ }^{31}$ EMX1 and NKX6-1 were identified as genes highly informative for detecting patients with gastric cancer among patients with past $H$. pylori infection with ORs of 23.8 and 15.0, respectively. ${ }^{32}$ The methylation levels of the three genes were analysed by quantitative methylation-specific PCR (qMSP), as previously described. ${ }^{31} 32$ Briefly, bisulfite modification was performed using $1 \mu \mathrm{g}$ of BamHI-digested genomic DNA. qMSP was performed with primer sets specific to methylated and unmethylated sequences by real-time PCR using SYBR Green I (BioWhittaker Molecular Applications, Rockland, Maine, USA) and an iCycler thermal cycler (Bio-Rad Laboratories, Hercules, California, USA). To correct for the variation in the number of methylated and unmethylated DNA molecules, depending upon the dilution of the standard DNA, two specific batches of control DNA (fully methylated and unmethylated DNA) were analysed in each qMSP analysis. All the samples were measured twice and the correlation of methylation levels in the two analyses was high (correlation coefficient $=0.94$ ).

\section{Statistical analysis}

Our study question was whether, at any time, the methylation level in gastric mucosae could predict the risk of gastric cancer and we counted person-years since the enrolment (ie, since the time of biopsy of gastric mucosa).

To analyse the relationship between the methylation levels and a risk of metachronous gastric cancer, all the patients were categorised into quartiles (Q) according to the methylation level of one of the three genes (miR-124a-3, EMX1 and NKX6-1), with the baseline characteristics of Q1 (lowest) and Q4 (highest) shown in table 1 . Since we assumed that a higher methylation level would be associated with a risk of metachronous gastric cancer, we estimated the HR and 95\% CI of Q4 compared with Q1 as the major goal.

Correlations between methylation levels of two genes were analysed using Spearman's rank correlation coefficient. Cox proportional hazard regression analysis was used to calculate univariate and multivariate-adjusted HRs (95\% CIs) of metachronous gastric cancer incidence. Kaplan-Meier analysis was
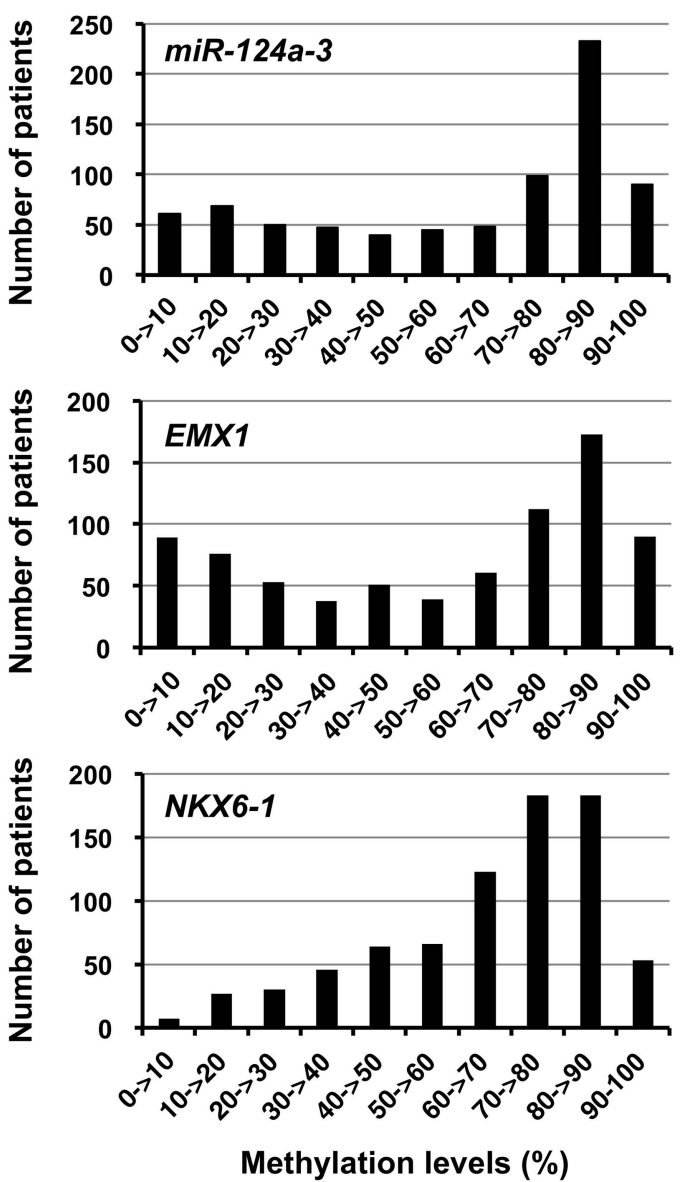

Figure 2 The distribution of methylation levels of miR-124a-3, EMX1 and NKX6-1 among the 782 patients. miR-124a-3 and EMX1 showed bimodal distributions, whereas NKX6-1 showed a unimodal distribution.

performed to compare development of metachronous gastric cancer in the four quartiles. The proportional hazard assumptions for the methylation level in comparing Q4 with Q1 were evaluated and met using graphical and time-dependent variable approaches. Analyses were conducted using the SAS statistical software, V.9.1 (SAS Institute Inc, Cary, North Carolina, USA). The results were considered significant when a $\mathrm{p}$ value $<0.05$ was obtained by two-sided tests.

In multivariate analysis, HRs were adjusted for potentially confounding factors (age $(<50,50-59,60-69$ or $\geq 70$ years), gender, pepsinogen index $((-)$, pepsinogen $\mathrm{I}>70$ or pepsinogen $\mathrm{I} / \mathrm{II}$ ratio $>3 ;(+)$, pepsinogen $\mathrm{I} \leq 70$ and pepsinogen $\mathrm{I} / \mathrm{II}$ ratio $\leq 3 ;(2+)$, pepsinogen $\mathrm{I} \leq 50$ and pepsinogen $\mathrm{I} / \mathrm{II}$ ratio $\leq 3 ;(3+)$, pepsinogen $\mathrm{I} \leq 30$ and pepsinogen $\mathrm{I} / \mathrm{II}$ ratio $\leq 2)$, smoking (0, $1-39$ or $\geq 40$ pack-years), green vegetable intake ( $\leq 2$ days, 3-4 days or almost daily), hospital (NCC, TYU or WMU), $H$. pylori infection before the enrolment (positive or negative) and past history of $\operatorname{ER}(0,1,2$ or 3 times)).

\section{RESULTS}

Enrolment and follow-up for a metachronous gastric cancer Among the 826 enrolled patients, 782 patients $(617,97$ and 68 patients at NCC, TYU and WMU, respectively) had at least one follow-up endoscopic examination (figure 1). Among the 782 patients, 81 patients $(59,10$ and 12 patients in NCC, TYU and WMU, respectively) developed a metachronous gastric cancer. Among the 81 patients, 15, 29, 16 and 21 patients developed a metachronous cancer in $<1,1-2,2-3$ and $\geq 3$ years after the 
Table 2 Correlation among methylation levels of miR-124a-3, EMX1, and NKX6-1

\begin{tabular}{|c|c|c|c|c|c|c|}
\hline & \multicolumn{2}{|c|}{$m i R-124 a-3$} & \multicolumn{2}{|c|}{$E M X 1$} & \multicolumn{2}{|c|}{$N K X 6-1$} \\
\hline & $r$ & p Value & $r$ & p Value & $r$ & p Value \\
\hline$m i R-124 a-3$ & - & - & 0.89 & $10^{-6}$ & 0.77 & $10^{-6}$ \\
\hline$E M X 1$ & 0.89 & $10^{-6}$ & - & - & 0.70 & $10^{-6}$ \\
\hline$N K X 6-1$ & 0.77 & $10^{-6}$ & 0.70 & $10^{-6}$ & - & - \\
\hline
\end{tabular}

enrolment, respectively, and 66 patients $(52,6$ and 8 patients in NCC, TYU and WMU, respectively) were considered to have authentic metachronous gastric cancers. The median follow-up period was 2.97 years $(2.99,2.51$ and 2.49 years in NCC, TYU and WMU, respectively). The median period for development of all the metachronous cancers after the enrolment was 1.88 years $(1.92,1.97$ and 1.32 years in NCC, TYU and WMU, respectively).

\section{Univariate analysis of the effect of methylation levels}

The methylation levels of miR-124a-3 and EMX1 showed bimodal distribution while that of NKX6-1 showed a unimodal distribution (figure 2). The methylation levels of the three genes were highly correlated (correlation coefficients $=0.70-0.89$; table 2), suggesting that methylation of these three genes reflected a shared mechanism, the epigenomic damage in gastric stem cells.
A univariate analysis using the authentic metachronous gastric cancers showed that Q4 (highest) miR-124a-3 methylation had a significantly higher HR than Q1 (lowest) (95\% CI) (2.17 (1.07 to 4.41); $\mathrm{p}=0.032$ ) ( $\mathrm{p}$ for trend=0.041) (table 3). The presence of the same trend in Q2 and Q3 with a trend $\mathrm{p}$ of 0.041 supported the higher HR in the Q4. Although not significant, similar trends were seen for EMX1 and NKX6-1 $(\mathrm{p}=0.075$ and 0.11 , respectively). A univariate analysis using all the metachronous gastric cancers also showed that Q4 miR-124a-3 methylation had a higher HR than Q1 $(95 \% \mathrm{CI})$ $(1.71(0.90$ to 3.22$) ; p=0.10)(p$ for trend $=0.094)($ table 3$)$.

The influence of known risk factors for gastric cancer (age, gender, pepsinogen index, smoking and green vegetable intake) and other potential risk factors (hospital, H. pylori infection before enrolment, past history of ER) was analysed using the authentic metachronous gastric cancers. Significant associations were seen for young age $(\mathrm{HR}(95 \% \mathrm{CI})=3.50(1.23$ to $10.0) ; \mathrm{p}=0.019)$, being female $(0.43(0.19$ to 1.00$) ; \mathrm{p}=0.049)$, past history of ER (5.66 (2.01 to 15.9$) ; \mathrm{p}=0.001)$ and smoking (2.24 (1.27 to 3.96); $\mathrm{p}=0.006)$ (table 4$)$. For all the metachronous gastric cancers, in addition to these factors, different hospitals had significantly different HRs (2.26 (1.21 to 4.21); $\mathrm{p}=0.01$ ).

\section{Multivariate analysis and Kaplan-Meier analysis}

A multivariate analysis was conducted by adjusting for hospital, gender, age, $H$. pylori infection before enrolment, pepsinogen index, past history of ER, smoking and green vegetable intake (table 5). Using the authentic metachronous gastric cancers, the

Table 3 Univariate HRs $(95 \% \mathrm{Cl})$ of quartiles of the three genes for a metachronous gastric cancer

\begin{tabular}{|c|c|c|c|c|c|}
\hline \multirow[b]{2}{*}{ Variable } & \multicolumn{4}{|c|}{ Quartile of DNA methylation level } & \multirow[b]{2}{*}{$p$ for trend } \\
\hline & Q1 (lowest) & Q2 & Q3 & Q4 (highest) & \\
\hline No. of patients & 195 & 196 & 196 & 195 & \\
\hline \multicolumn{6}{|c|}{$\begin{array}{l}\text { Authentic metachronous gastric cancers } \\
\text { miR-124a-3 }\end{array}$} \\
\hline No. of events & 12 & 17 & 15 & 22 & \\
\hline $\mathrm{HR}(95 \% \mathrm{Cl})$ & 1 & 1.26 (0.60 to 2.65$)$ & 1.17 (0.55 to 2.51$)$ & 2.17 (1.07 to 4.41$)$ & 0.041 \\
\hline$p$ Value & & 0.53 & 0.68 & 0.032 & \\
\hline \multicolumn{6}{|l|}{$E M X 1$} \\
\hline No. of events & 12 & 17 & 16 & 21 & \\
\hline $\mathrm{HR}(95 \% \mathrm{Cl})$ & 1 & 1.47 (0.70 to 3.08$)$ & 1.30 (0.62 to 2.76$)$ & 2.03 (1.00 to 4.14$)$ & 0.075 \\
\hline$p$ Value & & 0.31 & 0.49 & 0.051 & \\
\hline \multicolumn{6}{|l|}{$N K X 6-1$} \\
\hline No. of events & 14 & 11 & 20 & 21 & \\
\hline $\mathrm{HR}(95 \% \mathrm{Cl})$ & 1 & $0.70(0.32$ to 1.54$)$ & 1.31 (0.66 to 2.60$)$ & $1.43(0.73$ to 2.82$)$ & 0.11 \\
\hline$p$ Value & & 0.37 & 0.44 & 0.30 & \\
\hline \multicolumn{6}{|c|}{$\begin{array}{l}\text { All metachronous gastric cancers } \\
\text { miR-124a-3 }\end{array}$} \\
\hline No. of events & 16 & 20 & 21 & 24 & \\
\hline $\mathrm{HR}(95 \% \mathrm{Cl})$ & 1 & $1.13(0.59$ to 2.19$)$ & 1.24 (0.65 to 2.38$)$ & 1.71 (0.90 to 3.22$)$ & 0.094 \\
\hline$p$ Value & & 0.71 & 0.52 & 0.10 & \\
\hline \multicolumn{6}{|l|}{$E M X 1$} \\
\hline No. of events & 16 & 20 & 19 & 26 & \\
\hline HR $(95 \% \mathrm{Cl})$ & 1 & 1.28 (0.66 to 2.48$)$ & 1.16 (0.60 to 2.26$)$ & 1.83 (0.98 to 3.42$)$ & 0.080 \\
\hline$p$ Value & & 0.46 & 0.66 & 0.058 & \\
\hline \multicolumn{6}{|l|}{$N K X 6-1$} \\
\hline No. of events & 18 & 16 & 24 & 23 & \\
\hline $\mathrm{HR}(95 \% \mathrm{Cl})$ & 1 & 0.81 (0.41 to 1.58 ) & 1.24 (0.67 to 2.29 ) & 1.23 (0.66 to 2.28 ) & 0.29 \\
\hline $\mathrm{p}$ Value & & 0.53 & 0.49 & 0.51 & \\
\hline
\end{tabular}


Table 4 Univariate HRs $(95 \% \mathrm{Cl})$ of known and potential risk factors for metachronous gastric cancer

\begin{tabular}{|c|c|c|c|c|c|c|}
\hline \multirow[b]{2}{*}{ Variable } & \multicolumn{3}{|c|}{ Authentic metachronous gastric cancers } & \multicolumn{3}{|c|}{ All metachronous gastric cancers } \\
\hline & No. of events & HR & $\mathrm{p}$ Value & No. of events & HR & p Value \\
\hline \multicolumn{7}{|l|}{ Hospital } \\
\hline NCC & 52 & 1 & & 59 & 1 & \\
\hline TYU & 6 & $1.03(0.44$ to 2.40$)$ & 0.95 & 10 & $1.43(0.73$ to 2.80$)$ & 0.30 \\
\hline WMU & 8 & $1.77(0.84$ to 3.73$)$ & 0.14 & 12 & 2.26 (1.21 to 4.21$)$ & 0.01 \\
\hline \multicolumn{7}{|l|}{ Age } \\
\hline$\geq 70$ & 27 & 1 & & 34 & 1 & \\
\hline$<50$ & 4 & $3.50(1.23$ to 10.0$)$ & 0.019 & 4 & 2.76 (0.98 to 7.79$)$ & 0.055 \\
\hline $50-59$ & 6 & $0.58(0.24$ to 1.39$)$ & 0.22 & 9 & 0.71 (0.34 to 1.48$)$ & 0.36 \\
\hline $60-69$ & 29 & 0.91 (0.54 to 1.54$)$ & 0.72 & 34 & $0.86(0.54$ to 1.39$)$ & 0.55 \\
\hline \multicolumn{7}{|l|}{ Gender } \\
\hline Male & 60 & 1 & & 74 & 1 & \\
\hline Female & 6 & $0.43(0.19$ to 1.00$)$ & 0.049 & 7 & 0.41 (0.19 to 0.89$)$ & 0.023 \\
\hline \multicolumn{7}{|l|}{ Pepsinogen index } \\
\hline$(-)$ & 28 & 1 & & 35 & 1 & \\
\hline$(+)$ & 5 & 2.18 (0.83 to 5.68$)$ & 0.11 & 6 & 1.88 (0.79 to 4.50$)$ & 0.15 \\
\hline$(2+)$ & 16 & 1.65 (0.89 to 3.06$)$ & 0.11 & 18 & $1.44(0.82$ to 2.55$)$ & 0.21 \\
\hline$(3+)$ & 17 & 1.56 (0.85 to 2.87$)$ & 0.15 & 22 & 1.54 (0.90 to 2.63$)$ & 0.12 \\
\hline \multicolumn{7}{|c|}{ H. pylori infection before the enrolment } \\
\hline Positive & 41 & 1 & & 31 & 1 & \\
\hline Negative & 25 & $1.02(0.61$ to 1.71$)$ & 0.94 & 50 & $0.93(0.58$ to 1.47$)$ & 0.74 \\
\hline \multicolumn{7}{|c|}{ Past history of ER (times) } \\
\hline 0 & 13 & 1 & & 16 & 1 & \\
\hline 1 & 43 & 1.18 (0.63 to 2.19$)$ & 0.6 & 49 & 1.10 (0.63 to 1.93$)$ & 0.74 \\
\hline 2 & 5 & 0.81 (0.29 to 2.29$)$ & 0.69 & 10 & 1.38 (0.62 to 3.04$)$ & 0.43 \\
\hline 3 & 5 & $5.66(2.01$ to 15.9$)$ & 0.001 & 6 & $5.46(2.13$ to 14.0$)$ & 0.0004 \\
\hline \multicolumn{7}{|c|}{ Smoking (pack-years) } \\
\hline 0 & 15 & 1 & & 18 & 1 & \\
\hline $1-39$ & 17 & $1.17(0.57$ to 2.40$)$ & 0.66 & 25 & 1.55 (0.85 to 2.83$)$ & 0.15 \\
\hline$\geq 40$ & 29 & 2.24 (1.27 to 3.96$)$ & 0.006 & 32 & 2.06 (1.21 to 3.50$)$ & 0.007 \\
\hline \multicolumn{7}{|c|}{ Green vegetable intake (per week) } \\
\hline$\leq 2$ days & 20 & 1 & & 25 & 1 & \\
\hline $3-4$ days & 25 & $0.67(0.37$ to 1.21$)$ & 0.18 & 32 & $0.69(0.41$ to 1.16$)$ & 0.16 \\
\hline Almost daily & 18 & $0.65(0.34$ to 1.23$)$ & 0.18 & 20 & $0.57(0.32$ to 1.02$)$ & 0.06 \\
\hline
\end{tabular}

Q4 (highest) miR-124a-3 methylation had a higher HR than Q1 methylation (95\% CI) (2.30 (1.03 to 5.10); $\mathrm{p}=0.042)$ ( $\mathrm{p}$ for trend=0.057). when all the metachronous gastric cancers were used, Q4 miR-124a-3 methylation also had a higher HR (95\%CI) (1.99 (0.97 to 4.09); $p=0.061)$ ( $p$ for trend=0.072). We also conducted a multivariate analysis using the HR of the Q4 with the combined Q1-Q3 as a reference (see online supplementary table S1) and confirmed an association between the high miR-124a-3 methylation level and the occurrence of authentic metachronous gastric cancers (HR $(95 \% \mathrm{CI})=1.95$ (1.11 to $3.43 ; \mathrm{p}=0.021)$ ).

Kaplan-Meier curves of the cumulative incidence rates of all the metachronous gastric cancers for patients were drawn for quartiles (Q1-Q4) of methylation levels for each of the three genes (miR-124a-3, EMX1 and NKX6-1) (figure 3 and see online supplementary figure S1). Q4 methylation had higher incidences of a metachronous gastric cancer for all the three genes compared with Q1 methylation.

\section{Analysis of potential confounding factors}

The influence of $H$. pylori infection status before the enrolment did not affect the occurrence of metachronous gastric cancers (table 4). However, taking its potential influence on the predictive power of the methylation level, we conducted a stratified analysis by the $H$. pylori infection status before the enrolment. The median methylation levels of the three marker genes were lower in patients without $H$. pylori infection than those in patients with $H$. pylori infection (see online supplementary table S2). In the stratified analysis, the Q4 (highest) miR-124a-3 methylation levels showed HRs (95\% CI) of 1.32 (0.37 to 4.77$)$ and $2.43(0.81$ to 7.32$)$ for the authentic metachronous gastric cancers in the patients with and without $H$. pylori infection, respectively (see online supplementary table S3).

The influence of a past history of ER on the predictive power of the methylation level was also analysed by stratifying patients according to this past history. Again, we observed consistent results in each stratum, although the $\mathrm{p}$ values were not statistically significant owing to the decreased numbers of events (see online supplementary table S4). Also, we analysed the variability in the time between the first ER and enrolment in each quartile (see online supplementary table S5). There were no increasing or decreasing trends in the time according to the marker quartiles. Additionally, we conducted a stratified analysis according 
Table 5 Multivariate-adjusted HRs $(95 \% \mathrm{Cl})$ for a metachronous gastric cancer according to DNA methylation levels of the three genes

\begin{tabular}{|c|c|c|c|c|c|}
\hline \multirow[b]{2}{*}{ Variable } & \multicolumn{4}{|c|}{ Quartile of DNA methylation level } & \multirow[b]{2}{*}{$p$ for trend } \\
\hline & Q1 (lowest) & Q2 & Q3 & Q4 (highest) & \\
\hline No. of patients & 195 & 196 & 196 & 195 & \\
\hline \multirow{2}{*}{\multicolumn{6}{|c|}{$\begin{array}{l}\text { Authentic metachronous gastric cancers } \\
\text { miR-124a-3 }\end{array}$}} \\
\hline & & & & & \\
\hline No. of events & 12 & 17 & 15 & 22 & \\
\hline $\mathrm{HR}^{*}(95 \% \mathrm{Cl})$ & 1 & 1.33 (0.60 to 2.93 ) & 1.15 (0.51 to 2.61$)$ & $2.30(1.03$ to 5.10$)$ & 0.057 \\
\hline $\mathrm{p}$ Value & & 0.49 & 0.73 & 0.042 & \\
\hline \multicolumn{6}{|l|}{$E M X 1$} \\
\hline No. of events & 12 & 17 & 16 & 21 & \\
\hline $\mathrm{HR}^{*}(95 \% \mathrm{Cl})$ & 1 & $1.56(0.71$ to 3.41$)$ & $1.21(0.55$ to 2.67$)$ & $1.88(0.86$ to 4.13$)$ & 0.20 \\
\hline $\mathrm{p}$ Value & & 0.27 & 0.64 & 0.11 & \\
\hline \multicolumn{6}{|l|}{$N K X 6-1$} \\
\hline No. of events & 14 & 11 & 20 & 21 & \\
\hline $\mathrm{HR}^{*}(95 \% \mathrm{Cl})$ & 1 & $0.76(0.33$ to 1.74$)$ & 1.39 (0.66 to 2.96$)$ & $1.52(0.72$ to 3.21$)$ & 0.12 \\
\hline$p$ Value & & 0.52 & 0.39 & 0.27 & \\
\hline \multicolumn{6}{|c|}{ All metachronous gastric cancers } \\
\hline \multicolumn{6}{|c|}{ miR-124a-3 } \\
\hline No. of events & 16 & 20 & 21 & 24 & \\
\hline $\mathrm{HR}^{*}(95 \% \mathrm{Cl})$ & 1 & 1.30 (0.64 to 2.64$)$ & 1.31 (0.65 to 2.64$)$ & 1.99 (0.97 to 4.09$)$ & 0.072 \\
\hline $\mathrm{p}$ Value & & 0.47 & 0.45 & 0.061 & \\
\hline \multicolumn{6}{|l|}{$E M X 1$} \\
\hline No. of events & 16 & 20 & 19 & 26 & \\
\hline $\mathrm{HR}^{*}(95 \% \mathrm{Cl})$ & 1 & 1.47 (0.74 to 2.95$)$ & 1.16 (0.58 to 2.34$)$ & 1.84 (0.92 to 3.67$)$ & 0.150 \\
\hline $\mathrm{p}$ Value & & 0.27 & 0.68 & 0.082 & \\
\hline \multicolumn{6}{|l|}{$N K X 6-1$} \\
\hline No. of events & 18 & 16 & 24 & 23 & \\
\hline $\mathrm{HR}^{*}(95 \% \mathrm{Cl})$ & 1 & 0.93 (0.46 to 1.87 ) & 1.41 (0.72 to 2.76$)$ & 1.42 (0.71 to 2.81$)$ & 0.19 \\
\hline$p$ Value & & 0.83 & 0.32 & 0.32 & \\
\hline
\end{tabular}

to the time between the first ER and enrolment $(>5$ or $\leq 5$ years) and observed a similar association in each stratum (see online supplementary table S4).

\section{DISCUSSION}

It was shown for the first time by a multicentre prospective cohort study that assessment of an epigenetic field defect using methylation levels can be used as a biomarker of cancer risk. This study warrants translation of previous retrospective crosssectional studies showing that methylation levels accumulated in various tissues are correlated with cancer risk. ${ }^{6} \quad \begin{array}{lllll}16 & 17 & 19 & 33 & 34\end{array}$ Thus, the intensity of surveillance for metachronous gastric cancer can be adjusted according to the risk predicted by the $m i R-124 a-3$ methylation level. In addition, methylation accumulation is known to be caused by exposure to its inducers, such as chronic inflammation, ${ }^{35}$ and cancer risk prediction using accumulated methylation is considered to take account of the life history of individuals. This point makes epigenetic cancer risk markers entirely different from genetic cancer risk markers, mostly single nucleotide polymorphisms, which cannot take account of the life history of individuals.

We defined the authentic metachronous gastric cancers because distinction of a metachronous cancer from that undetected at the time of the enrolment is difficult when it is detected at 1 year after the enrolment. ${ }^{28-30}$ Also, metachronous gastric cancer developing within 1 year after enrolment might have been influenced by the promoting effect of $H$. pylori infection. ${ }^{26}$ Analyses using both the authentic and all the metachronous gastric cancers were conducted and a clearer difference was seen using the authentic metachronous gastric cancers. For example, the methylation level of $m i R-124 a-3$ was associated with development of an authentic metachronous gastric cancer with significant $p$ values of 0.032 and 0.042 by univariate and multivariate analyses, respectively. This supported the hypothesis that the presence of an epigenetic field defect is associated with occurrence of independent multiple cancers.

The quality of this translational study was supported by multiple parameters. The follow-up rate of patients enrolled in this study was high $(97.9 \%$; 809/826). The median follow-up period reached 2.97 years and was uniform in the three hospitals. Accordingly, the bias introduced by incomplete follow-up is minimised. Also, all the patients were followed up with a consistent interval of 1 year in the three participating hospitals. This is reflected in the Kaplan-Meier curves, which show that the incidence of a metachronous gastric cancer increases every 1 year. Further, even after adjusting for multiple variables, the influence of methylation levels on the occurrence of authentic metachronous gastric cancer was significant. The fact that two variables (gender and smoking) known to be associated with gastric cancer risk ${ }^{36}$ were confirmed as independent risk factors supported the statement that collection of lifestyle information was appropriately conducted in this study. 

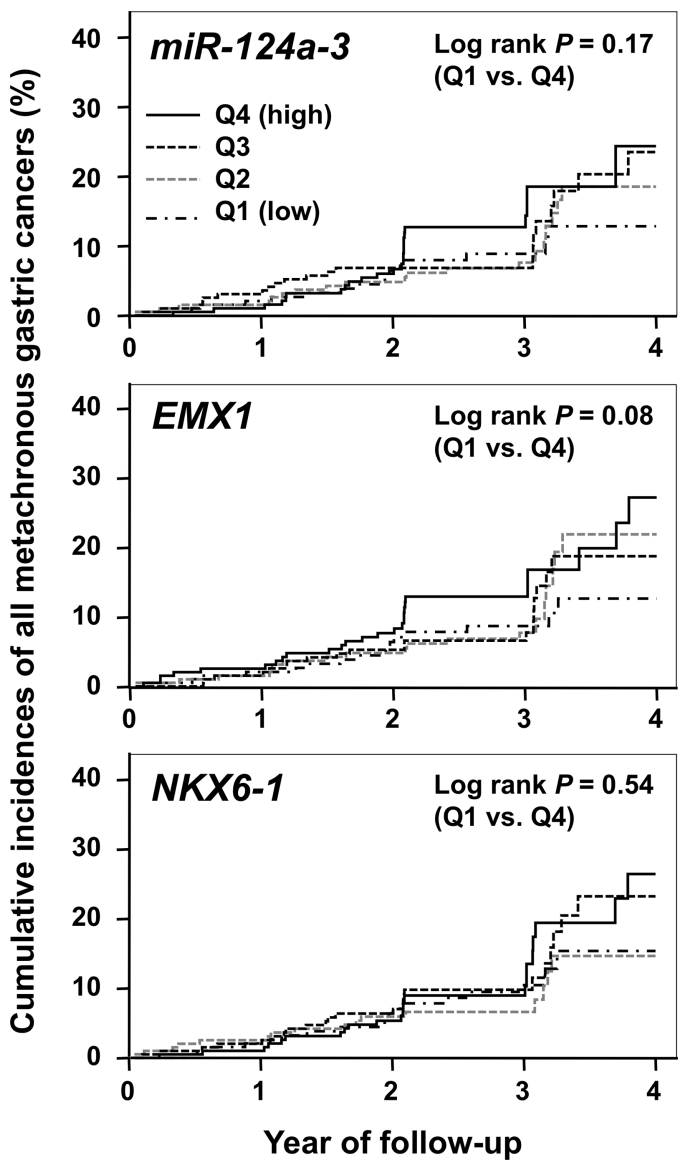

Figure 3 Cumulative incidence of all the metachronous gastric cancers for patients in quartile (Q1-Q4) of methylation levels of miR-124a-3, EMX1, and NKX6-1. The Q4 methylation had higher incidences of a metachronous gastric cancer than the Q1 methylation with $p$ values of $0.17,0.08$ and 0.54 for miR-124a-3, EMX1 and NKX6-1, respectively, by the log-rank test.

Nevertheless, several limitations of the study should be mentioned. First, the patient population was heterogeneous at enrolment for the past history of ER or the years since the first ER. These factors were associated with the occurrence of metachronous gastric cancer (table 4). Therefore, in addition to the multivariate analysis involving these factors, we conducted analyses stratified by these factors and found consistent results in each stratum, although the results were not statistically significant owing to the limited number of events (see online supplementary table S4). Thus, it is unlikely that these factors biased the association between the quartiles of $m i R-124 a-3$ and metachronous gastric cancer. Second, owing to a relatively small number of events, inevitable for a prospective study of cancer risk, we could not conclude which pattern, dose-response or threshold pattern, was obeyed by the relationship between methylation level of $m i R-124 a-3$ and cancer risk. However, we found an association of miR-124a-3 with authentic gastric cancer risk for the Q4 (highest) using Q1 (lowest) or the combination of all the other quartiles (Q1-Q3) as a reference (table 5 and see online supplementary table S1). This finding may support the threshold curve. Since the incidence of a metachronous gastric cancer is stable long after $\mathrm{H}$. pylori eradication, ${ }^{25} 37$ further long-term follow-up is expected to strengthen the correlation and clarify an appropriate model of relationship.

From a molecular viewpoint, we tried to measure the accumulation of aberrant methylation in stem cells by analysing gastric mucosae without $H$. pylori infection, at least 6 months after H. pylori eradication. It is known that the methylation level in gastric mucosa decreases after $H$. pylori eradication, ${ }^{21-23}$ and that the persistent methylation level in gastric mucosa without H. pylori infection is correlated with gastric cancer risk. ${ }^{14} 1924$ Since methylation induced in stem cells can only persist for a long time without its inducer, the methylation level in gastric mucosa without $H$. pylori infection could be considered to reflect epigenomic damage accumulated in stem cells. However, we do not have direct evidence to support the hypothesis, because it is still impossible to analyse DNA methylation of specific genes in histological sections. The higher methylation level and smaller HR in patients with $H$. pylori infection before the enrolment (see online supplementary table S3) might have indicated that the methylation levels had not reached baseline after eradication and were superimposed with methylation in progenitor cells.

We analysed three preselected marker genes. Ideal marker genes should be methylated in parallel with overall methylation levels of driver genes in stem cells, but at much higher levels for accurate measurement. $m i R-124 a-3$ is a tumour-suppressor gene (driver gene) with relatively high methylation levels, ${ }^{31}$ and was considered to have met the criteria. Two other genes (EMX1 and NKX6-1) were homeobox genes and considered to be passenger genes. In addition to the analysis using the methylation level of a single gene, we performed an exploratory analysis by combining methylation of three marker genes. Simple addition of the methylation levels of the three genes did not improve the prediction power (data not shown). However, when we scored the number of genes within the Q4 (highest) using the three marker genes, the patients with the highest scores displayed a high HR (95\% CI) (2.23 (1.12 to 4.44); $\mathrm{p}=0.022$ ) with a statistically significant trend $\mathrm{p}$ of 0.038 using the authentic metachronous gastric cancers. The smaller $p$ value in this combined analysis also supports a threshold model.

In our previous study, we performed biopsies from three positions (antrum, middle body and upper body). ${ }^{19}$ It was shown that methylation levels of the three positions were different and that their mean had the highest association with gastric cancer risk. However, patients with a high mean methylation level had higher methylation levels in any of the three positions. In the current study, we performed biopsy from one position, considering the merits (smaller risk of bleeding) and demerits (less precise reflection of the cancer risk) of limiting the positions of biopsy. Since the utility of epigenetic analysis of gastric tissue was demonstrated here, an increase of biopsy positions in future studies may be considered.

In summary, the methylation level of $m i R-124 a-3$ was associated with an increased risk of developing metachronous gastric cancers. Assessment of an epigenetic field defect using methylation levels in normal tissue is a promising biomarker for cancer risk that takes account of life history.

Acknowledgements The authors are grateful to Dr Shigetaka Yoshinaga and Dr Haruhisa Suzuki for patient follow-up and to Eiken for measuring serum pepsinogen levels and serum anti-H. pylori antibody levels of all the patients.

Collaborators Shigetaka Yoshinaga; Haruhisa Suzuki.

Contributors TU, TN, MF and MI conceptualised the study. KA, TA and SN performed the experiments. TN, NY, TM, CY, IO, TY, MF, TG and MI followed up the patients endoscopically. TS carried out data analysis. TU and KA wrote the manuscript.

Funding This study was supported by a grant-in-aid for pioneering basic research from the Ministry of Health, Labour (H20-genome-g-006) and Welfare and by a National Cancer Center Research and Development Fund (H23-A-2), Japan. 


\section{Competing interests None.}

Patient consent Written informed consent was obtained from all the patients.

Ethics approval Study approved by the institutional review board at each hospital.

Provenance and peer review Not commissioned; externally peer reviewed.

Open Access This is an Open Access article distributed in accordance with the Creative Commons Attribution Non Commercial (CC BY-NC 3.0) license, which permits others to distribute, remix, adapt, build upon this work non-commercially, and license their derivative works on different terms, provided the original work is properly cited and the use is non-commercial. See: http://creativecommons.org/ licenses/by-nc/3.0/

\section{REFERENCES}

1 Rodriguez-Paredes M, Esteller M. Cancer epigenetics reaches mainstream oncology. Nat Med 2011;17:330-9.

2 Baylin SB, Jones PA. A decade of exploring the cancer epigenome-biological and translational implications. Nat Rev Cancer 2011;11:726-34.

3 Ushijima T. Epigenetic field for cancerization. J Biochem Mol Biol 2007;40:142-50.

4 Grabsch HI, Tan P. Gastric cancer pathology and underlying molecular mechanisms. Dig Surg 2013;30:150-8.

5 Kondo Y, Kanai Y, Sakamoto M, et al. Genetic instability and aberrant DNA methylation in chronic hepatitis and cirrhosis-a comprehensive study of loss of heterozygosity and microsatellite instability at 39 loci and DNA hypermethylation on $8 \mathrm{CpG}$ islands in microdissected specimens from patients with hepatocellular carcinoma. Hepatology 2000;32:970-9.

6 Nishida N, Nagasaka T, Nishimura T, et al. Aberrant methylation of multiple tumor suppressor genes in aging liver, chronic hepatitis, and hepatocellular carcinoma. Hepatology 2008;47:908-18.

7 Eads CA, Lord RV, Kurumboor SK, et al. Fields of aberrant CpG island hypermethylation in Barrett's esophagus and associated adenocarcinoma. Cancer Res 2000;60:5021-6.

8 Jin Z, Cheng Y, Gu W, et al. A multicenter, double-blinded validation study of methylation biomarkers for progression prediction in Barrett's esophagus. Cancer Res 2009;69:4112-15.

9 Cui H, Cruz-Correa M, Giardiello FM, et al. Loss of IGF2 imprinting: a potential marker of colorectal cancer risk. Science 2003;299:1753-5.

10 Hsieh CJ, Klump B, Holzmann K, et al. Hypermethylation of the p16INK4a promoter in colectomy specimens of patients with long-standing and extensive ulcerative colitis. Cancer Res 1998;58:3942-5.

11 Issa JP, Ahuja N, Toyota M, et al. Accelerated age-related CpG island methylation in ulcerative colitis. Cancer Res 2001;61:3573-7.

12 Azuara D, Rodriguez-Moranta F, de Oca J, et al. Novel methylation panel for the early detection of neoplasia in high-risk ulcerative colitis and Crohn's colitis patients. Inflamm Bowel Dis 2013;19:165-73.

13 Yan PS, Venkataramu C, Ibrahim A, et al. Mapping geographic zones of cancer risk with epigenetic biomarkers in normal breast tissue. Clin Cancer Res 2006;12:6626-36.

14 Maekita T, Nakazawa K, Mihara M, et al. High levels of aberrant DNA methylation in Helicobacter pylori-infected gastric mucosae and its possible association with gastric cancer risk. Clin Cancer Res 2006;12:989-95.

15 Nishiyama N, Arai E, Chihara Y, et al. Genome-wide DNA methylation profiles in urothelial carcinomas and urothelia at the precancerous stage. Cancer Sci 2010;101:231-40.

16 Lee $\mathrm{YC}$, Wang HP, Wang $\mathrm{CP}$, et al. Revisit of field cancerization in squamous cell carcinoma of upper aerodigestive tract: better risk assessment with epigenetic markers. Cancer Prev Res (Phila) 2011:4:1982-92.

17 Shen L, Kondo Y, Rosner GL, et al. MGMT promoter methylation and field defect in sporadic colorectal cancer. J Natl Cancer Inst 2005:97:1330-8.
18 Kang GH, Lee S, Cho NY, et al. DNA methylation profiles of gastric carcinoma characterized by quantitative DNA methylation analysis. Lab Invest 2008;88:161-70.

19 Nakajima T, Maekita T, Oda I, et al. Higher methylation levels in gastric mucosae significantly correlate with higher risk of gastric cancers. Cancer Epidemiol Biomarkers Prev 2006;15:2317-21.

20 Niwa T, Tsukamoto T, Toyoda T, et al. Inflammatory processes triggered by Helicobacter pylori infection cause aberrant DNA methylation in gastric epithelial cells. Cancer Res 2010:70:1430-40.

21 Chan AO, Peng JZ, Lam SK, et al. Eradication of Helicobacter pylori infection reverses E-cadherin promoter hypermethylation. Gut 2006:55:463-8.

22 Perri F, Cotugno R, Piepoli A, et al. Aberrant DNA methylation in non-neoplastic gastric mucosa of $H$. pylori infected patients and effect of eradication. Am J Gastroenterol 2007;102:1361-71.

23 Nakajima T, Enomoto S, Yamashita S, et al. Persistence of a component of DNA methylation in gastric mucosae after Helicobacter pylori eradication. J Gastroenterol 2010;45:37-44.

24 Shiotani A, Murao T, Uedo N, et al. Eradication of H. pylori did not improve abnormal sonic hedgehog expression in the high risk group for gastric cancer. Dig Dis Sci 2012;57:643-9.

25 Nakajima T, Oda I, Gotoda T, et al. Metachronous gastric cancers after endoscopic resection: how effective is annual endoscopic surveillance? Gastric Cancer 2006:9:93-8.

26 Fukase K, Kato M, Kikuchi S, et al. Effect of eradication of Helicobacter pylori on incidence of metachronous gastric carcinoma after endoscopic resection of early gastric cancer: an open-label, randomised controlled trial. Lancet 2008:372:392-7.

27 Moertel CG, Bargen JA, Soule EH. Multiple gastric cancers; review of the literature and study of 42 cases. Gastroenterology 1957:32:1095-103.

28 Hosokawa O, Tsuda S, Kidani E, et al. Diagnosis of gastric cancer up to three years after negative upper gastrointestinal endoscopy. Endoscopy 1998;30:669-74.

29 Voutilainen ME, Juhola MT. Evaluation of the diagnostic accuracy of gastroscopy to detect gastric tumours: clinicopathological features and prognosis of patients with gastric cancer missed on endoscopy. Eur I Gastroenterol Hepatol 2005;17: 1345-9.

30 Kato M, Nishida T, Yamamoto K, et al. Scheduled endoscopic surveillance controls secondary cancer after curative endoscopic resection for early gastric cancer: a multicentre retrospective cohort study by Osaka University ESD study group. Gut 2013;62:1425-32.

31 Ando T, Yoshida T, Enomoto $\mathrm{S}$, et al. DNA methylation of microRNA genes in gastric mucosae of gastric cancer patients: its possible involvement in the formation of epigenetic field defect. Int I Cancer 2009;124:2367-74.

32 Nanjo S, Asada K, Yamashita $\mathrm{S}$, et al. Identification of gastric cancer risk markers that are informative in individuals with past $H$. pylori infection. Gastric Cancer 2012;15:382-8.

33 Takamaru H, Yamamoto E, Suzuki H, et al. Aberrant methylation of RASGRF1 is associated with an epigenetic field defect and increased risk of gastric cancer. Cancer Prev Res (Phila) 2012;5:1203-12.

34 Shin CM, Kim N, Park JH, et al. Prediction of the risk for gastric cancer using candidate methylation markers in the non-neoplastic gastric mucosae. J Pathol 2012;226:654-65.

35 Ushijima T, Hattori N. Molecular pathways: involvement of Helicobacter pylori-triggered inflammation in the formation of an epigenetic field defect, and its usefulness as cancer risk and exposure markers. Clin Cancer Res 2012;18: 923-9.

36 Gonzalez CA, Agudo A. Carcinogenesis, prevention and early detection of gastric cancer: where we are and where we should go. Int I Cancer 2012;130:745-53.

37 Maehata Y, Nakamura S, Fujisawa K, et al. Long-term effect of Helicobacter pylori eradication on the development of metachronous gastric cancer after endoscopic resection of early gastric cancer. Gastrointest Endosc 2012;75:39-46. 